\title{
Communications with Customers in the Service Industry: A Case of Service Sales Manual Development
}

\author{
Hyemi Hwang', Dohee Kwon ${ }^{2}$
}

${ }^{1}$ Sahmyook University, Seoul, Korea
${ }^{2}$ Youngsan University, Pusan, Korea

Objectives: This study aims to introduce a development case of empirical service manuals utilized by service corporations and help service managers and leaders for their future effective management on moment of truth (MOT).

Methods: In order to develop a duty-free service manual, the 2019 MOT monitoring evaluation, customer satisfaction survey, voice of customers, and a previous service manual developed in 2013 were analyzed. The requirements of executives and managers were taken into consideration. The service standards were set with the cooperation of subject matter experts, and the contents of the service manual were revised to reflect the opinions of employees.

Results: The standard behaviors and guidelines at each stage of the sales process were organized, and the best cases for sales conversations were shared at the first and the second workshops. The developed service manual was distributed to the division managers and the sales directors, and training was provided for effective use of the manual.

Conclusions: The developed manual is used for the employees to teach them about the service process and customer service skills during their customer satisfaction training and the new employee training. A developed service manual should be utilized by employees not only published as a booklet. In order to promote the implementation of service manuals in a real MOT, the continuous monitoring of employee's behavior according to the service manual and immediate feedback on employee performance are required.

Key Words: Service Manual, Standardization, Service Quality, Customer Satisfaction, Duty-Free Service

\section{Introduction}

The delivery of service is an interaction between front-line employee and customer (Czepiel, Solomon, Surprenant, \&

Received: Feb 4, 2020 Revised: May 4, 2020 Accepted: May 19, 2020

Corresponding author: Dohee Kwon

5101, E dong, Youngsan University, Haeundae Campus,

142 Bansongsunhwan-ro, Haeundae-gu, Busan 48015, Korea

Tel: +82-51-540-7070, E-mail: dhkwon@ysu.ac.kr

This is an Open Access article distributed under the terms of the Creative Commons Attribution Non-Commercial License (http://creativecommons.org/licenses/ by-nc/4.0/) which permits unrestricted non-commercial use, distribution, and reproduction in any medium, provided the original work is properly cited.

Copyright $(\odot) 2020$ Korean Association for Business Communication.
Gutman, 1985; Solomon, Surprenant, Czepiel, \& Gutman, 1985 ), and this encounter of customers assessing and evaluating the quality of service is often considered a "moment of truth (MOT)" (Carlzon , 1987). The service has unique characteristics such as intangibility (Bebko, 2000), heterogeneity, inseparability, and perishability (Jaw, Lo, \& Lin, 2010). Thus, front-line employee-customer interaction needs to be carefully designed, managed, and controlled (Victorino, Verma, Bonner, \& Wardell, 2012) to promote the custumer satisfaction.

There is a variation in the ability and competence of each employee who delivers the service, and the service needs to be customized according to the customer's properties and situations (Time, Place, Occasion, T.P.O.) while being delivered. Standard- 
ization of services can prevent mistakes and deviations in providing customized services, maintaining reliability, helping management control, enhancing consumer protection, and raising confidence and satisfaction among consumers (Jones, Nickson, \& Taylor, 1994; Kasiri, Cheng, Sambasivan, \& Sidin, 2017). Service companies develop the standard manual of customer service to train their employees to provide consistent service. In order to operate and manage the service process effectively and clearly, standards for service behavior and communication must be set for the employees to follow when responding to customers, and based on the findings, an employee service evaluation at MOT should be practiced.

The concept of customer satisfaction and service in Korea was first introduced in the early 90 s by large companies such as Samsung, LG and Hyundai. At that time, service meant unconditional kindness. In other words, the customer was king, and the customer was always right, and the service-related staff always had to have a bright smile, friendly greeting, polite speech, and professional appearance when providing service. Thus, the content of the service manual were based on five items of service: a decent appearance and attire of the staff, a bright facial expression and voice, an appropriate posture and gesture, case by case greetings (customer service), and desirable conversation expressions starting from the 1990s until around the early 2000s.

At the beginning of the early 2000s, service companies realized the importance of managing customer waiting times (Kim \& Yoo, 2010) and responding to complaints after purchases and started systematic service processes and quality control. Top service companies aligned their service concept, service manual, and service monitoring together. However, most companies have set manuals by rearranging related contents from existing literature and managed them according to the experience and criteria of service executives without establishing proper evaluation criteria.

Since it has been only over a decade since the service delivery process has been recognized as a process in Korea, companies still lack the ability to manage and operate service processes effectively from within, so they often rely on external experts to maintain the existing level of service standard without any new improvements or innovations. Service process management and standardization methods for each service company are conducted in a variety of ways. Service process management and standardization methods should be conducted in a way that is optimized for each company's business model.

In this service management field, there are theories about service process and service standardization, but there is little research and knowledge about service manuals that companies can practically utilize. Therefore, in this study, we would like to share the development process and main contents of a service manual as a tool to increase the value of the service provided to customers and reinforce the positive customer experience in the case of a duty-free shop. This case study is expected to be helpful for the service company managers and field leaders when confronting MOT in the future.

\section{Case Description}

\section{Need for Duty-Free Shops to Develop a Service Manual}

To develop a duty-free service manual, we analyzed the results of the 2019 MOT monitoring evaluation, customer satisfaction survey, and voice of customers (VOC); reviewed the contents of the service manual developed in 2013; and constructed the development concepts by reflecting the requirements of management and representatives. As a result of the overall review, we agreed to develop a manual that blends services and sales to reinforce the customer experiences and analyzed the service level evaluation results. We found that a high proportion of new employees did not perform basic service behavior properly such as posture and greetings. The manual gives concrete examples of actions that must be followed and actions to be avoided when responding to customers.

Service manuals should contain guidelines on employee behavior and conversations that must be performed at MOT. Furthermore, manuals should be constantly upgraded to meet evolving customer needs. The most important thing in developing a service manual is to establish the development concept and direction.

First of all, the focus was on reinforcing the positive customer experience following the service management trend. We studied ways to increase the positive experiences of our customers and diminish uncomfortable and unpleasant experiences. Analyzing the service level evaluation results confirmed that a high proportion of new employees did not perform basic service behavior properly such as posture and greetings. Therefore, this manual proactively suggests the actions that must be followed and actions that must be avoided when responding to customers.

The second is the activation of internal communication. Although the existing manual consisted of an external customer service, we tried to deal with an effective communication method from the viewpoint of the internal customer who is the main subject of service. In addition to the dialogue for working with internal employees, we have included conversation skills for better work coordination, an emotional workers protection act, information for the emotional care of employees based on occupational safety and health acts, and proposed solutions for 
the effective use of service sales manuals as well as sharing the content of field practitioners was provided.

\section{Contents of the Service Sales Manual}

The main dialogue method of the service sales manual of a duty-free shop consists of four areas, focusing on actions and dialogue expressions that identify and actively respond to customer's needs (Table 3).

\section{Part 1: Standard Behavior and Guidelines for Services by Phase}

In the greeting phase, we proposed a dynamic standby method to welcome customers, and in the identifying needs phase, we organized questioning, listening, and empathy techniques to ask the customer what they need. In the problem solving phase, we proposed three ways (trend, diversity, and convenience) to make the product look appealing to customers. In the payment/ product delivery phase, A/S, exchange, refund-related instructions were sorted, and in the farewell phase, a method of sending customers off politely was explained.

\section{Part 2: Skills and Conversations to Strengthen Sales Capability}

\section{1) Question: SPIN Technique}

SPIN (Situation, Problem, Implication, Needs-Pay Off) techniques are sales skills to strengthen sales capability developed by Huthwaite, a global sales consulting company, by analyzing more than 35,000 sales consultation cases in more than 50 industries, including GE, Kodak, Xerox, Volvo, and Motorola (Rackham, 1988). As customers have different characteristics and tastes, it is important to ask the right questions to understand what their needs are.

Appropriate situational questions (S) help employees to understand the customer's current situation, and problem questions $(\mathrm{P})$ help them to explore customer dissatisfaction or problems. Through implication questions (I) that can recognize and share problems, customers feel that their problem is perceived to be important. As the last type, needs-pay off questions $(\mathrm{N})$ that can solve problems allow customers to be confident when purchasing the product while considering its benefits.

In addition, by using the extended questions to ask the customers how they feel after using the product, the customers can find the product they want and they can recommend the product with the appropriate alternative. It is difficult to understand unless the customer expresses what is on their mind. Questions can be asked to assist in identifying the detailed needs that the customer did not recognize and allow them to become self-enlightened rather than having staff appeal the advantages of the product so that customers gain confidence in their product choices by themselves.

\section{2) Product Description: FABE Technique}

FABE (Feature, Advantage, Benefit, Evidence) techniques are widely used to increase the effectiveness of proposal descriptions as a way for employees to describe products. The FABE technique emphasizes the features, advantages, and benefits of the products when describing the product. Rather than listing all the characteristics of the product, it is important to explain the highlighted and representative features and benefits that can be perceived by the target audience to attract attention. Specific evidences such as product purchasing cases, statistics, and reviews can be provided to eliminate anxiety before a purchase and lead to decision making.

For example, when selling a rose gold watch to customers, it is effective to highlight the color and design of metal watches (features and advantages) as well as customer's personality and easy-to-layer points (benefits) with fashion. In addition, emphasizing the popularity of the watch with the fact that it receives a great deal of customers' interests and inquiries (evidence) confirms the watch to be the best model at the department store.

\section{3) Alternative Proposal: 3F Technique}

In situations where it is difficult to answer such as when a customer is looking for products that are out of stock or limited, employees are encouraged to explore why the customer is looking for a particular product and find a solution using $3 \mathrm{~F}$

Table 3. Contents in the service sales manual

\begin{tabular}{|c|c|c|}
\hline Part & Phase & Contents \\
\hline 1 & $\begin{array}{l}\text { Establish standard behavior and guidelines } \\
\text { for service sales by phase }\end{array}$ & $\begin{array}{l}\text { Service point by phase: Greetings, identifying needs, problem solving, payment/delivery, } \\
\text { and farewells. }\end{array}$ \\
\hline 2 & $\begin{array}{l}\text { Develop skills and communication to } \\
\text { strengthen sales capabilities }\end{array}$ & $\begin{array}{l}\text { Sharing best practices such as using questions, product description, and offering } \\
\text { alternatives. }\end{array}$ \\
\hline 3 & $\begin{array}{l}\text { Develop dialogue methods for each sales } \\
\text { section }\end{array}$ & $\begin{array}{l}\text { Discovering major sales dialogue methods such as cosmetics, fashion, sunglasses, liquor, } \\
\text { red ginseng, watches, etc. }\end{array}$ \\
\hline 4 & $\begin{array}{l}\text { Develop problem-solving skills according to } \\
\text { the situation }\end{array}$ & Responding to complaints and malicious customers (according to emotional labor law). \\
\hline
\end{tabular}


(Feel-Felt-Found) technique. After fully understanding why customers are looking for a particular product, employees need to recommend a product that suits their needs. An "Empathy-Identifying the fact-Suggesting alternative" approach might be helpful. As shown in Table 4, a swift alternative proposal can upset customers. For example, if a customer asked, "Why is this so expensive?" and the employee answered, "Items on sale are over there," then how would the customer feel? They may feel insignificant. Therefore, it is important to remember to show empathy first even if it is a difficult situation to deal with. However, it is a good idea to avoid showing excessive empathy immersing in a customer's situation. This is because insincere empathy rather leads to counter-productivity.

\section{Part 3: Sales Methods by Item Groups}

Part 3 includes detailed sales methods for different item groups such as cosmetics, perfumes, cigarettes, red ginseng, sunglasses, liquor, watches, etc. This part includes up-selling techniques to suggest higher class products, cross-selling techniques to recommend additional products, and how to give customers confidence in their choices.

For example, when an employee sells cosmetics, it is important to ask questions about the customer's skin concerns and then compare and describe different products. Recommendations are given to customers to try other products that are more functional or can be used together with the products they are looking for. This will broaden their choices and prevent them from regretting purchase decision making. In addition, when the customer is hesitant about purchasing a product because they are unfamiliar with the product, the employee allows the customer to test the cosmetics themselves or to facilitate the customer's purchasing decisions by mentioning other customers' reviews and its popularity.

The most difficult thing for employees to overcome is challenging opposition. It is not easy to persuade a customer when they compare the product to other brands or have a negative previous experience with the product. When a customer makes an argument, listen to the customer and professionally compare prices, performance, and effectiveness. Make sure that customers recognize the difference in familiarity that have made them feel uncomfortable with the product and not make it due to a product defect.

\section{Part 4: How to Respond with Problem-Solving Skills by Situation}

Finally, part 4 is the last phase of the service sales manual that consists of handling complaints from customers and malicious customers. Employees can follow the procedure and process accordingly in the cases of a simple complaint, a complaint about the product and service, physical abuse, or a verbally abusive customer so that they can wisely solve problems rather than unconditionally apologize for every situation.

Service manuals make employees use apologies too often in every situation, resulting in employees' having low self-esteem and low job satisfaction. For example, when a customer asks for a name, "Excuse me, what's your name?" is appropriate, not "I'm sorry, what's your name?"

When handling malicious customers, we organized a company's support and effort for the employees' protection. In the event of verbal abuse, sexual harassment, or emotional exhaustion, the staff at MOT is separated from the customer for the physical safety and psychological comfort, and the service will be temporarily suspended. Inform the staff at MOT that the problem caused with the customer is not the employee's personal fault, and conduct interviews and consultations to prevent emotional depression or exhaustion. If a customer's verbal abuse or sexual harassment is deemed to be in violation of criminal penalties of the relevant law, the staff can report it to the competent agency if the staff at MOT who have been affected by the act requests to do so. This series of content "serves," as a foundation to the service staff at MOT that "allows" employees to enjoy meeting customers under the company's interest and protection.

\section{Discussion}

Service companies suggest the scope and order of the service delivery process for staff at MOT through the service manual

Table 4. Example dialogue for difficult situation: In case of specific volume is not in stock

\begin{tabular}{lll}
\hline Step & Action & Example dialogue \\
\hline 1 & Empathy & $\begin{array}{c}\text { Yes, I understand you are looking for a smaller version of the product. } \\
\text { I regret to inform you that if there were a wider range of choices for the product, we would have had a wider } \\
\text { selection for you. }\end{array}$ \\
& $\begin{array}{c}\text { Explaining the fact/ } \\
\text { exploring the reason }\end{array}$ & $\begin{array}{c}\text { Unfortunately, only } 1 \text { bottle per person is allowed to be purchased at the Duty-Free store, and therefore, we } \\
\text { carry mostly big bottles. Are you looking for something to enjoy at home? }\end{array}$ \\
& $\begin{array}{c}\text { Alternative proposal/ } \\
\text { product suggestion }\end{array}$ & $\begin{array}{c}\text { Even if it is a big bottle, I can assure you that it is cheaper than the smaller bottle sold outside the Duty-Free } \\
\text { store. I guarantee that you will not regret this purchase if you take advantage of this great price. }\end{array}$ \\
\hline
\end{tabular}


and specify the responsibilities of the performance. Staff at MOT have the advantage of increasing job skills and sharing information through documented manuals, and companies can secure skilled personnel through manuals and reduce losses caused by department transfer (Suh \& Lee, 2012). Companies are building and implementing their own manuals, but in order to meet the changing needs of customers and reduce dissatisfaction, they need to improve the level of execution in the longterm perspectives rather than temporary manual execution.

Therefore, the link between the service concept, service manual, and service monitoring (evaluation) is the most important, and the service concept should be implemented as a behavioral point and dialogue expression in the manual. Employees who are monitored can rely on the evaluation if the service concepts and manuals are consistent.

Giese and Cote (2000) conceptualized customer satisfaction to be an emotional or cognitive response, with a focus on subjective perspectives such as customer expectations and experiences. They also claimed that the response occurred not only when using the service, but also after decision making, purchase, or even after several experiences. Therefore, it is necessary to focus on the customer's response and experience at the time of service delivery during the development of the service sales and to reinforce the customer's positive experience and to improve the behavior and dialogue technique of employees to minimize a negative experience. This is because the ability of the employees to solve problems and communicate with the customers at MOT determines the level of service quality. In general, it is necessary to find moments when customers can evaluate the service of companies and employees in order to develop situational dialogue at MOT. Look for moments when customers feel confident.

In addition, it is important to understand the expectation and state of customer's mind in order to effectively manage MOT. Specifically, employees need to understand the customer's state of mind on a case-by-case basis and consider their expectations to find solutions. In a study of the competency indicators of face-to-face service staff at MOT, Lee and Hwang (2018) argued that employees need to have self-management, the ability to control emotion and customer orientation, as well as communication skills, the ability to cope with the situation and confidence-building skills in order to effectively respond.

The service sales manual can be useful guidelines that provide the dialogue expression that helps to communicate with customers smoothly and identify the points of behavior to cope with unintended situations that occur at the point of the conversation. Manuals also can increase the sales power of the sales product. The conversation to respond flexibly to difficult situa- tions can be a useful guide to overcome the customer's opposition. Moreover, a service sales manual can enhance the ability to build trust with the customer giving reliability through accurate work process when complaints are raised about the delay of waiting time, service, and products from the customer.

\section{Conclusion}

Through the service sales manual development process, we can identify and solve problems of communication between departments, improving work cooperation and work efficiency among internal employees. The developed manual is used to ensure that customer satisfaction training and new employee training by department is used to acquire service processes and to provide customer service. Based on this manual, monitoring to evaluate the level of on-site service is carried out and the level of service manual understanding of the staff can be verified.

A developed manual should be actively utilized, not only published and finished as a booklet. Manual training for consistent and constant implementation of manuals should be carried out continuously and each department should strive to train multi-tasking personnel through distinctive and various manual training for acquisition. Staff at MOT who practice the actual manual must be compensated according to their ability and execution. By monitoring the manual execution process in real situations, its direct effect on increasing the level of manual execution can be obtained and linked with feedback and work performance by monitoring the manual execution process.

\section{References}

Bebko, C. P. (2000). Service intangibility and its impact on consumer expectations of service quality. Journal of Services Marketing, 14(1), 9-26.

Carlzon, J. (1987). Moments of truth. Cambridge, MA: Ballinger.

Czepiel, J. A., Solomon, M. R., Surprenant, C. F., \& Gutman, E. G. (1985). Service encounters: An overview. In J. A. Czepiel, M. R. Solomon, C. F. Surprenant, \& E. G. Gutman (Eds.), The service encounter: Managing employee/customer interaction in service businesses (pp. 3-15). Lexington, MA: Lexington Books.

Giese, J. L., \& Cote, J. A. (2000). Defining consumer satisfaction. Academy of Marketing Science Review, 1(1), 1-27.

Jaw, C., Lo, J. Y., \& Lin, Y. H. (2010). The determinants of new service development: Service characteristics, market orientation, and actualizing innovation effort. Technovation, 30(4), 265-277.

Jones, C., Nickson, D., \& Taylor, G. (1994). "Ways" of the world: Managing culture in international hotel chains. In A. V. Seaton, C. L. Jenkins, R. C. Wood, P. U. C. Dieke, M. M. Bennett, L. R. Ma- 
cEllan, \& R. Smith (Eds.), Tourism: The state of the art (pp. 626634). Chichester, UK: John Wiley \& Sons.

Kasiri, L. A., Cheng, K. T. G., Sambasivan, M., \& Sidin, S. M. (2017). Integration of standardization and customization: Impact on service quality, customer satisfaction, and loyalty. Journal of Retailing and Consumer Services, 35, 91-97.

Kim, J. Y., \& Yoo, B. M. (2010). An exploratory study on customers' individual factors on waiting experience. Asia Marketing Journal, 12(1), 1-30.

Lee, S. K., \& Hwang, H. M. (2018). An exploratory study on the development of competency indicators of person-to-person service encounter employees. Journal of Korea Service Management
Society, 19(4), 159-179.

Rackham, N. (1988). SPIN selling. New York, NY: McGrw-Hill.

Suh C. J., \& Lee B.R. (2012). The study of factors affecting to MOT employees on service industry to handle service manual. Proceedings of the 2012 Fall Conference of the Service Management Society (pp. 81-104). Daejeon, Korea.

Solomon, M. R., Surprenant, C., Czepiel, J. A., \& Gutman, E. G. (1985). A role theory perspective on dyadic interactions: The service encounter. Journal of Marketing, 49(1), 99-111.

Victorino, L., Verma, R., Bonner, B., \& Wardell, D. (2012). Can customers detect script usage in service encounters? An experimental video analysis. Journal of Service Research, 15(4), 390-400. 